\title{
Racing Toward Uncertainty: an Ethico-Aesthetics of Imagination
}

\section{Jack Kahn}

Pomona College: Claremont, California

\begin{abstract}
In this paper, I examine imagination as a performative expression using an ethico-aesthetic paradigm (which I take from Baruch Spinoza and Félix Guattari) which accounts for the ways, affects, as ethical orientations toward the world, participate in creative world-making amidst conditions of social and political entrapment. Using William James' notion of "medical materialism" as a critical tool, I turn to the work and life of South Asian autistic poet Tito Mukhopadhyay to trouble the ways critical discourse understands 'autism'. These are namely as a signifier for particular reductive perceptuo-aesthetic relations (an understanding I find in the work of Erin Manning), in order to re-conceive how disability politics might resist and restructure totalizing systems of global domination without referring to rights or identity claims.
\end{abstract}

\section{Keywords/Terms}

Disability, autism, ethico-aesthetics, affect, world-making, imagination, medical materialism, embodiment, perception, neuro-reductionism, performativity, entrapment, crisis

\section{Correspondence information:}

Jack.Kahn@Pomona.edu 


\section{Introduction: On Autism and Ethico-Aesthetics}

Discourse frequently describes autism as an "enigma." But what would it mean for one to live within enigma, for one's body to be cast as a riddle, a puzzle, a question? To think through autism would compel not simply an analysis of its construction within discourse, but an analysis of what it means to be immersed within and to respond to the realities and entrapments created by the interactions between the cultural and the embodied. That which "autism" signifies exceeds its definition by diagnostic criteria, which comprehends autistic difference as a pervasive social and developmental pathology that disables those who embody it. Definitions of autism which understand it simply as a signifier for neural difference insufficiently address the embeddedness of that which we refer to as "autism" within the worlds of those whom it describes. An analysis of autism must remind us that, while constructed within medical discourse, "autism" imbricates with the flesh, performatively creating autistic worlds - the spaces of people's lives. Not simply a relation or even a perceptual modality, autism is an assemblage of meanings, matters, subjects, bodies, and lives. Autism describes a condition, a position within the world charted by medical meaning but not totally determined by it. To simply be "autistic" is to be performatively identified as autistic (either by the self or others), but to live artistically involves expressing a lively autistic selfhood which exceeds medical description.

In order to contemplate the lived registers of autism, I take theories of affect into consideration. I insist upon a thoroughly Spinozist conception of affect, one concerned not simply with emotion or structures of feeling, but with the capacity of bodies to relate and become. Affects are orientations toward the world, orientations which create worlds. Not simply emotive feeling, affect involves ways of being. Such an understanding of affect avoids reductive ableist assumptions involving a normative modality with which to process feeling (I do believe that many affect discourses assume normative affective or emotive relations, a concern outside the scope of my analysis). A consideration of the affective dimensions to life can therefore speculate how we can relate differently and, by relating differently, imagine new worlds-insisting against normative understandings which render certain bodies as hopelessly inert, non-relational, and incapable of agential activity.

It is for this reason that I wish to consider an ethico-aesthetics, a paradigm which Sha Xin Wei defines as one within which "every action or utterance is to be construed not as a description-imitation thrice removed-of the world, but a making of the world" (20) ${ }^{7}$. Within such a paradigm, I read artistic expressions not as mimetic reflections of life, but as lively forms in themselves, as operations which participate in the unfolding of lives. Therefore, I wish to understand aesthetics not as subjective judgment, but as an event, a moment, or an encounter, as a creative doing, entangled with the world. Ethico-aesthetics 
resonates with Deleuze's assertion that - "Herein, perhaps, lies the secret: to bring into existence and not to judge. If it is so disgusting to judge, it is not because everything is of equal value, but on the contrary because what has value can be made or distinguished only by defying judgment. What expert judgment, in art, could ever bear on the work to come?" $(135)^{2}$. Involving not a judgment of aesthetic value, ethico-aesthetics considers creative expression as ethics, as ways of being in the world. Therefore, I practice ethico-aesthetics in order to consider how autistic aesthetic expressions, autistic ways of being, do not foreclose relation, but open relation by imagining new worlds. I find such a concern for how the poetics of experience engage radical world-making within the work and life of Tito Mukhopadhyay. I want to consider Mukhopadhyay's poetry not as a reflection of autistic experience or as an articulation of autistic identity, but as an imaginative engagement with the world which participates in its ethical re-structuring, in a disability politics premised not upon representation or identity, but upon hopeful imagination and ethical relationality. I wish to analyze the political conditions from which Mukhopadhyay's work emerges, not to reduce his poetics to a reflection of his political milieu, but to investigate the political possibilities imagined by his poetic engagement with the world. An ethico-aesthetics of Mukhopadhyay's poetics can therefore read his expressions not as a reductive representation of autism, but as a world-making proposalas an embodiment of a relation to the world which resists the pathologizing conditions that reduce autistic experience to its presumed neural origins. Such presumptions render autistic individuals as objects to cure or understand-a conjecture which Mukhopadhyay resists through the erotics of language. Therefore, Mukhopadhyay practices art, not to simply poetically capture his world, but to ethically inhabit and transform it, thereby proposing a disability politic that is not premised on rights or identity claims.

\section{A Mother's Grasp, A Woman in Crisis: Defining Neuro-reductionism}

Poet and non-verbal autistic Tito Mukhopadhyay grew up in Mysore and Bangalore with his mother, Soma Mukhopadhyay, who notably developed the "rapid prompting method", a technique to teach autistic children certain written and verbal skills ${ }^{3}$. Portia Iverson of Cure Autism Now (or CAN, now merged with Autism Speaks) invited the Mukhopadhyay's to the United States when Tito was 14 years old, so that he could participate in American scientific autism studies and so Soma could impart her teaching methods to American educators ${ }^{4}$.

Iverson, wife of Hollywood producer Jon Shestack, formed CAN after the autism diagnosis of her son, Dov, and upon learning not only that autism had no cure, but that there were very few researchers working to develop a cure for autism. "I

felt helpless to help [Dov]," Iverson stated to CBS News, "and yet, every minute, every day, I saw him getting further and further out of my grasp and there was no expert out there to stop it" $(n p)^{5}$. Iverson describes her helpless feeling through a metaphoric of her body, the grasp. The metaphor of grasping conjures 
a scenario where Dov passively gets further from Iverson's motherly grasp, the space of her capacity to relate, without naming the force (the emergence of autistic behaviors) which compels such a falling-from-grasp. The vehicle of Iverson's grasp, the zone around her body within which she could hold an object, describes the metaphorical tenor, a capacity, the limit of Iverson's ability to understand or care for her son, the limits of her capacity to relate. "Grasp" delineates the possibilities of relation available in order to suggest that Dov's autism impedes his mother's grasp, foreclosing the possibility of relation.

Iverson's not-yet-actual non-autistic child (which Iverson implicitly presumes to be her "true" son) passes into a dark, opaque futurity, disappearing into illegibility and non-relationality. Dov's movement over the threshold of one existential territory to another characterizes the eventful crisis of his fallingfrom-grasp. The unspoken pathology of autism here represents Iverson's inability to "reach" her son, rendering autism as a state of non-relationality outside the human grasp. Iverson's metaphor brings to mind Maurice Blanchot's pronouncement in The Writing of the Disaster that: "In the relation of myself to the Other, the Other exceeds my grasp" $(19)^{6}$. Discourses which pathologize neurological difference orient Iverson's genuine feeling of caring, helplessness, and love for her child away from the uncomfortable alterity of the autistic Other, denying its radical difference by rendering it intelligible through a narrative of sickness and healing. Iverson deploys such narratives to try to hold autistic difference within the grasp of her understanding-a gesture which Ralph James Savarese would define as "neuro-reductionist."

Iverson presents herself as a woman in crisis. Lauren Berlant writes: "the deployment of crisis is often explicitly and intentionally a re-definitional tactic, a distorting or misdirecting gesture that aspires to make an environmental phenomenon appear suddenly as an event because as a structural or predictable condition it has not engendered the kinds of historic action we associate with the heroic agency a crisis seems already to have called for" $(760)^{8}$. In this scenario, the heroic expert, whose job is to interrupt the emergence of danger, fails to halt the event of the autistic child's passage from his mother's grasp. Iverson's "true" son, the non-autistic one to whom she could relate, exists now only as a possibility which belongs to a particular futurity, an imagined temporal zone wherein society has immunized itself from crisis, the random pathogenic emergence of autistic difference. Within this future, the normative relays of social being can remain uninterrupted by chance, so we might conceive of it as not transformative but progressive, an expansion and therefore re-instantiation of the present rather than its re-imagination. Neuroreductionism, and its rendering of autistic emergence as a crisis-event, redirects Iverson's desire to relate to her son toward this particular teleology, the completion of a particular futurity wherein Dov is not autistic. This maneuver constructs the autistic body as an object to be explained, cured, and examined, containing it within medical discourse, and mobilizing it for its own cure project-a project which 
becomes coherent only through the construction of the diseased body and the pathogenicity of autism.

\section{The Race toward Certainty: Neuroreductionism, Economy, and Racialization}

Iverson had heard of the successes that Soma Mukhopadhyay "won" with regard to teaching her son how to communicate with neurotypicals, feeling hopeful that Soma's methods could teach Dov normative language skills. On CAN's sponsorship of the Mukhopadhyay's to the United States, Ralph James Savarese writes: "CAN was all too happy to champion Tito as evidence of what is possible for 'severely' autistic children, its primary focus was to raise funds to develop a cure-in short, to eradicate the difference that is autism" (np) ${ }^{9}$. CAN's interest in Mukhopadhyay invested mostly in his capacity to produce poetic yet coherent (as defined by neurotypical norms of written coherence) writing insofar as it could promote its institutional agenda (and its aggressive promotion of what the autistic community refers to as "cure culture") by reigning the attention of both the international scientific establishment and the allistic media, which understood Tito's writing as a signifier for the mystery of the human mind, the unexpectedly "rich" internal lives of autistic people, and the will of the determined spirit to "reach out" to his environment despite great odds" Stuart Murray writes that " $[t]$ he fact that Tito can write at all is central to the [advertising] campaigns that point to his ability to overcome; what he might have to say seems of secondary importance" (149) ${ }^{11}$. Emotional appeals regarding Tito's "miraculous" capacity to write occlude any other aspect of his poetry. The framing of Mukhopadhyay's work by the non-profit industrial complex, attach particular bewildered or enchanted affects to his work, producing a sort of allure which attracts attention to their advertising campaigns. Therefore, the affective economies within which CAN participates operationalize Tito's poetry to harness feeling and attention (through advertisement campaigns) in the interest of promoting cure culture and the national immunization from autism.

Mukhopadhyay's movement across continents and hemispheres attests to CAN's investments in Tito not as an autistic subject, but in the alterity of his body both as a signifier and as a resource for medical progress. Whiteness and allism simultaneously construct the brown autistic body of Mukhopadhyay as mysterious and opaque, valorizing it for its location just outside the grasp of colonial knowledge. Cure culture, with its attachments to the non-profit industrial complex and global capitalism, values the "diseased" autistic body not in terms of its capacity to perform labor, but for the information it may extract from it. Organizations such as CAN understand autistic individuals as not-yetcured laborers or as bodies from which the medical apparatus can learn. On Kaushik Sunder Rajan's formulation of "bio-capital" and capitalism's investment in the information it could glean from biological material, Jasbir Puar writes: "If the value of a body is increasingly sought not only in its capacity to labor but in the information that it yields-and if there is no such thing as excess, 
or excess info, if all information is eventually used or is at least seen as having imminent utility - we might ask whether this is truly a revaluing of otherwise worthless bodies left for dying" (164) ${ }^{12}$. According to Puar, neoliberal regimes of capital accumulation invest in understandings of the pathologized body in terms of what it might glean from its medical surveillance, and that this revaluing of the diseased body might seem ostensibly inclusive, but it is premised still upon the pathologization of certain bodies and their exclusion from full subject-hood. Mukhopadhyay's body becomes valuable to only because it can produce certain effects for advertisement campaigns (which raise money to help reproduce the medical apparatus), and because under conditions of medical surveillance it might lend researchers information about autistic difference. The autistic body becomes useful to the non-profit and medical industrial complexes as an object for circulating affects and as a resource for data extraction, for knowledge production. Cure culture might compel an interest in Mukhopadhyay, a revaluation of his importance to neoliberal regimes of capital accumulation within the non-profit industrial complex, but only insofar as he might benefit marketing interest and ultimately medical research as an object of surveillance.

The medical agenda of CAN alienated Mukhopadhyay, and he and his mother eventually severed ties from the organization. Tension between the Mukhopadhyay's and Portia Iverson culminated in the unflattering representation of Tito in Iverson's autobiography, Strange Son. Savarese writes that, in Strange Son, "Iverson depicts [Mukhopadhyay] as 'beastly,' as an 'alien being,' and as 'possessed by a demon'-descriptors that work to emphasize the purportedly awful 'behaviors' of autism and, hence, the urgent need for a cure" $(\mathrm{np})^{13}$. Savarese neglects to mention the racialized dimensions of Iverson's description. By connecting him with animality, Iverson renders Tito as something radically other than the white son fallen from her grasp. Tito's racialized embodiment already forecloses his capacity to achieve proper citizenship, as his autism is not the only facet of his being which might discursively connect him to the alien, the beast, or the monstrous. Iverson must portray Tito as a racialized monstrosity not only to underscore the pathogenicity of autism, but also to describe his positionality as a racialized not-quite-subject whose body matters only for the information which it could yield to her medical agenda, the potential realization of proper subject-hood by white not-yet-cured autistics and the immunization efforts of global white supremacy. The affective valence of Tito's representation within media shifts according to the operations of cure culture, which must regard the autistic body as a puzzle to understand, a pathogenic monstrosity to disgust, or as a not-yet-subject to cure.

\section{A Life within Medical Entrapment: Poetics amidst Neuroreductionism}

Mukhopadhyay writes poetically about his interactions with the medical apparatus, proposing imagination as a resistant tactic to respond to the conditions of entrapment which pose him as an enigmatic object to be explained 
through medical surveillance. In "Poem 1" from The Mind Tree, Mukhopadhyay writes:

\author{
"Men and women are puzzled by everything I do \\ Doctors use different terminologies to describe me \\ I just wonder \\ The thoughts are bigger than I can express \\ Every move that I make shows how trapped I feel \\ Under the continuous flow of happenings \\ The effect of a cause becomes the cause of another effect \\ And I wonder \\ I think about the times when I change the environment around me \\ With the help of my imagination \\ I can go places that do not exist \\ And they are like beautiful dreams. \\ But it is a world full of improbabilities \\ Racing toward uncertainty" (173)
}

Mukhopadhyay notices the felt confusion of medical and scientific professionals in response to his embodiment. "Men and women are puzzled by everything I do," Tito writes, "Doctors use different terminologies to describe me. ${ }^{15}$ " The constantly changing terms deployed by doctors to make sense of Tito's perceptual experience demonstrates how the autistic body constantly interrupts the meaning-making processes by which medicine attempts to render it legible. Tito turns internally, "I just wonder/ The thoughts are bigger than I can express. 16" Tito's contemplations exceed his expressive capacity, his ability to render his cognition legible through expressions which might be received by a world which privileges norms of communication that exclude his body.

The condition of his inability to convey his thoughts to those around him produces a sense of entrapment:"Every move that I make shows how trapped I feel/ Under the continuous flow of happenings/ The effect of a cause becomes the cause of another effect. ${ }^{7}$ "' Tito's movements, expressions which capture the creativity of his thought, fail to signify anything other than his autism which itself signifies entrapment and non-relationality. Time appears to Tito as a continuous unfolding of contingent happenings-wherein events contain future events which themselves contain future events-that do not involve his agential action. In other words, the conditions of medical surveillance position him as an object entirely for regimes of knowledge production, enclosing him within a deterministic temporal field of cause and effect.

Mukhopadhyay speaks to the tendency to explain the behaviors of autistic people through what William James refers to as "medical materialism," or the "discrediting [of] states of mind for which we have an antipathy" through medicalized discourses of the body (143) ${ }^{18}$. James argues that one ought not to 
conflate the study of an object's origin with an assessment of its value, asserting that existential judgment, an inquiry into how an object came about, is entirely different from a study of its value. James' discourse concerns the medical discounting of religious experience, such as the invalidation of the Quaker religion by locating its origin in George Fox's presumed schizophrenia, but I find it useful because "medical materialism" colludes with neuroreductionism. In fact, I shall use the two terms almost interchangeably.

The construction of behaviors as "autistic" empties them of any possible signification other than medical meaning because it pathologizes such behaviors, pointing to its (speculative) material origin within the autistic body. The condition of autistic difference explains behaviors based on hypothetical pathogeneses, what might have happened materially to the body to cause autistic phenomena, poising the autistic subject in a position wherein her speech represents only her neurological difference (about which medicine does not entirely know). Medical materialism understands the expressions of autistic people as evidence of their original neurological difference.

I find a noteworthy example of neuroreductionism within Erin Manning's book, Always More than One: Individuation's Dance. Manning builds from Alfred North Whitehead's process philosophy and Gilbert Simondon's theory of individuation to explore autistic perception as one which includes a greater awareness of a relational field prior to the so-called allistic tendency to "chunk" or entrain experience into categorically predetermined subjects and objects ${ }^{19}$. For Manning, "autism" signifies this particular difference. "Autism" represents a relation to the world that provides "a transversal, ontogenetic concept of the ethical," one which "can never begin with the human, or with the body as such" (255) ${ }^{20}$. Manning's analysis reduces "autistic" experience to a generic conceptual ethico-aesthetic relation as well as a rubric for non-correlationist thought, conflating the value of autistic expressions (which are, I suppose, to help neurotypical people theorize perception) with an analysis of their presumed origin. "Autism" becomes an ethic, but also a metaphor for a sort of allure, an almost magical enchantment with the world-reducing Mukhopadhyay's poetic experiences to an example or a model of aesthetic relation.

Manning writes of Mukhopadhyay that his "experience of the world, even as he is capable of articulately composing with literary pasts and futures, continues to dwell in the now of experience in the making" $(160)^{21}$. What interests Manning is the spectacular difference of Mukhopadhyay's experience, which attaches a fantastical valence to "autism," a thoroughly neuro-reductionist gesture. How Mukhopadhyay actively participates in the creation of the now in which he dwells is of less interest to Manning than the fact of his different situatedness within time as a result of his perceptual difference. Mukhopadhyay's poetry cannot represent autistic perception, which, like neurotypical perception, is variegated and cannot be reduced to a reductive relational rubric. Manning's 
analysis, however, reduces Mukhopadhyay to a signifier for autism, losing the lived richness of his active participation within the world, even while she attempts to speak to (or perhaps, for) the validity of autistic perception. Such an analysis conflates autism with its origin, to a sort of "primitive" perceptual difference from which an autistic experience might emerge, even while Manning might argue for the richness of such an autistic experience. Autism becomes, for Manning, a metaphor, an alluring object for the consideration of other means. While her analysis interestingly demonstrates how many autistic individuals creatively express forms of difference that are outside to correlationist perceptual modalities which entrain their environments into discrete subjects and objects, Manning nonetheless recapitulates the neuro-reductionist tendency to understanding autistic experience as enigmatic or enchanting. I am interested, instead, in how autistic individuals, such as Mukhopadhyay, resist discursive totalities which violently operationalize his difference in the interest of knowledge production.

\section{Imagination, Possibility, Lines of Flight: Resisting Neuro-reductionism}

We can understand Tito's entrapment as an effect of the medical totalities which hold him in place as an object to be examined, cured, or explained. To address such conditions of entrapment, Tito considers moments when he transforms his environment with his imagination: "And I wonder/ I think about the times when I change the environment around me/ With the help of my imagination. ${ }^{22 "}$ Mukhopadhyay deploys metric form in order to render his imaginations as resistant expressions. The repeated use of the word "wonder" within lines three and eight suggests the persistence of Tito's wonderment and the capacity of his imaginations to resist capture, to remain durably resistant against totalities which are structured upon its erasure. Composed of trochaic dimeter, lines three and eight punctuate the poem, which is written in free verse, interrupting Mukhopadhyay's ruminations with two instances of organized metric form. Tito's use of poetic form, therefore, reinforces an insistence that aesthetics engages in a practice of organizing the poetics of experience within a process of world-making. As Alfred North Whitehead notes within his Dialogues: "Art... is the imposing of a pattern on experience, and our aesthetic enjoyment in recognition of the pattern" (228-9 ${ }^{23}$. In the form of trochaic meter, Mukhopadhyay's wonderment imposes pattern upon his experiences, suggesting the capacity of imaginative wonder to weave expressive organization into the world not only to produce aesthetic enjoyment, but also to engage his environment transformatively-to respond to his experiential milieu in such a way that participates in its formal restructuring. The persistence of wonderment (which persistently imposes short instances formal organization into his poetry) amid the uncertainties of Mukhopadhyay's doctors and the uncertainties of his imagined futures, imposes aesthetic organization onto the present, opening a space for Mukhopadhyay to inhabit and transformatively reorient himself amid medical entrapment. 
Mukhopadhyay's imaginings undo the medical norms which hold the body within a particular contingency of cause and effect, rupturing epistemological totalities which might enable subjects to feel certain of what is or what can; "I can go places that do not exist/ And they are like beautiful dreams./ But it is a world full of improbabilities/ Racing toward uncertainty24". Tito's poetics draw a line of flight, an operation which overwhelms the field of discourses and practices that construct a normal shared reality, gesturing dangerously toward the realm of the not-yet-possible. Tito meditates upon the poetics of experience and their capacity to recreate the world in creative new trajectories. Tito's being and surviving, the conditions of his phenomenological experience and his relation to his environment, reconfigure prevailing epistemologies which hold reality in its place-a condition which I would like not to romanticize, but to take seriously as a strategy for living within, acting upon, and resisting an environment structured upon the erasure of one's agency and personhood.

In his imaginations, Mukhopadhyay embodies a daring hopefulness, an intensification and deepening of the present which opens new possibilities for relation, for new futurities. Mukhopadhyay's imaginations do not recede from the world; rather, they express an openness to relation, to the unfolding of new futures. Such an openness might appear to the neurotypical person as a retreating, an escape from relation, however, as autistic writer Mel Baggs (formerly known as Amanda Baggs) reminds us in their 2007 video, "In My Language," the imposition of neurotypical communicative norms actually entrap many autistics, foreclosing their capacity to relate: "Ironically, the way that I move / when responding to everything around me / is described as 'being in a world of my own' / whereas if I interact with a much more limited set of responses / and only react to a much more limited part of my surroundings / people claim that I am / 'opening up to true interaction with the world" $(n p)^{25}$. Therefore, we might conceive imagination as an expressive act which performatively transforms the body's relational capacities, a maneuver that transmutes ones position within temporalities and worlds. Such an act embodies an ethico-aesthetic decision to reorient oneself away from structured totalities or narratives, and toward possibility. Félix Guattari argues that-"there is an ethical choice in favour of the richness of the possible, an ethics and politics of the virtual that de-corporealizes and de-territorializes contingency, linear causality and the pressure of circumstances and significations which besiege us. It is a choice for processuality, irreversibility and re-singularization."(94) ${ }^{26}$ Mukhopadhyay, by imaginatively restructuring his environment amid medical entrapment, ethically participates in the restructuring of the present. Tito's poetry meditates upon the vital capacity of imagination to transform the present by turning toward vital futurities, embodying an ethics which ruptures the totalities that enable the deterministic temporal field of medical entrapment, those forces which collude with the negation of his subject-hood. Tito's imaginations conjure virtualities which actively territorialize the present, actualizing the world along trajectories which breach those facilitated by those 
forces which trap him.

\section{Conclusion: Autistic Futures}

Mukhopadhyay embodies a hopefulness toward futurity, not simply through feeling, but through an imaginative orientation to the world which radically and dangerously insists against neuro-reductionist entrapment. Jasbir Puar, expanding on Brian Massumi, defines hope as "a capacity, emblematic of a futurity that speaks to the body's tendency to be affected or affecting, its capacity for change, evolution, transformation, and movement. This capacity is likewise the basis for the force of political transformation that does not rely on identity politics, or any particular model of social movement, but a different kind of resistance." (162) ${ }^{27}$ Mukhopadhyay's resistant strategies involve not an articulation of an autistic selfhood (at least in this instance), but a radical, poetic world-making involving an openness to uncertain futurities. Such a resistant affective orientation itself opens up possibility by intensifying and deepening the present, an initial step toward ushering in radically restructured not-yet-imagined worlds. "Poem 1" does not simply represent Mukhopadhyay's hopeful imaginations, but is itself a lively hopeful form and a resource for political transformation. The aesthetic form of Mukhopadhyay's poem embodies the hopefulness that Puar describes in that it emerges from the space of Mukhopadhyay's life, participating in his ethical transformation of the present and future. However, I look to Mukhopadhyay's poetic expressions in the world not as a potent space to re-imagine politics, nor do I take his imaginations as a figure for the consideration of how to structure alternative modes of resistance. Instead, I wish to seriously consider the ways in which, through an attentiveness to the body's capacity for change, we can rethink how bodies can or might relate in order to more ethically enable the imaginative world-making tendencies of others.

\section{Notes}

1 Sha, Xin Wei. Poiesis and Enchantment in Topological Matter. Cambridge, MA: MIT, 2012. Print.

2 Deleuze, Gilles. Essays Critical and Clinical. Minneapolis: U of Minnesota, 1997. Print. 
3 I use the term "non-verbal" to mean that Mukhopadhyay's preferred modes of communication do not involve verbal speech produced by organs such as the mouth and vocal chords (which has nothing to do with his capacity to form language). Many identify Mukhopadhyay as non-verbal though he can use vocal speech to communicate with those familiar with his voice, leading me to believe that the labeling of verbal capacity is usually meant to "place" someone on the autism spectrum without using so-called "functioning labels," which have been virulently critiqued by the autistic community. This points to the difficulty of defining autistic people's capacities in relation to their ability to fulfill neurotypical norms, such as using verbal speech to communicate, and I question the necessity to do this-although I also find it important to describe Mukhopadhyay as "nonverbal" (instead of others labels, such as "severely" or "low-functioning" autistic) as it defines so heavily how his body is rendered in discourse.

${ }^{4}$ Autism Speaks has been criticized by the autistic community for prioritizing medical cures over providing important services for autistic adults. As an individual who is autistic himself, I find the stated agenda of Autism Speaks to be reprehensible and offensive.

${ }^{5}$ Kohn, David. "Breaking The Silence: One Woman's Drive to Teach Her Autistic Son." CBS News. CBS Interactive, 14 Jan. 2003. Web. 26 Oct. 2014.

${ }^{6}$ Blanchot, Maurice. The Writing of the Disaster (L'ecriture Du Désastre). Lincoln: U of Nebraska, 1986. Print.

7 Savarese, Ralph James. "Toward a Postcolonial Neurology: Autism, Tito Mukhopadhyay, and a New Geo-poetics of the Body." Journal of Literary \& Cultural Disability Studies 4.3 (2010): 273-89. Web.

8 Berlant, Lauren. "Slow Death (Sovereignty, Obesity, Lateral Agency)." Critical Inquiry 33.4 (2007): 754-80. Web.

9 Ibid.

10 I use "allistic" to mean non-autistic. "Allism" describes the condition of being allistic. I also use the term "allism" to refer to the ideologies and structures which collaborate to stigmatize autism whilst simultaneously naturalizing and privileging allistic individuals and behaviors.

11 Murray, Stuart. Representing Autism: Culture, Narrative, Fascination. Liverpool: Liverpool UP, 2008. Print.

12 Puar, Jasbir K. "Prognosis Time: Towards a Geopolitics of Affect, Debility and Capacity." Women \& Performance: A Journal of Feminist Theory19.2 (2009): 161-72. Web. 
13 Savarese, Ralph James. "Toward a Postcolonial Neurology: Autism, Tito Mukhopadhyay, and a New Geo-poetics of the Body." Journal of Literary \& Cultural Disability Studies 4.3 (2010): 273-89. Web.

${ }_{14}$ Mukhopadhyay, Tito Rajarshi. The Mind Tree: A Miraculous Child Breaks the Silence of Autism. New York: Arcade Pub., 2003. Print.

15 Ibid.

16 Ibid.

17 Ibid.

18 James, William. The Varieties of Religious Experience: A Study in Human Nature. N.p.: Arc Manor LLC, 2008. Print.

19 Manning, Erin. Always More than One: Individuation's Dance. Durham: Duke UP, 2013. Print.

20 Ibid.

21 Ibid.

22 Mukhopadhyay, Tito Rajarshi. The Mind Tree: A Miraculous Child Breaks the Silence of Autism. New York: Arcade Pub., 2003. Print.

${ }^{23}$ Whitehead, Alfred North, and Lucien Price. Dialogues of Alfred North Whitehead. Boston: Little, Brown, 1954. Print.

24 Ibid.

25 Baggs, Mel. "In My Language." YouTube. YouTube, 14 Jan. 2007. Web. 01 Dec. 2014.

${ }^{26}$ Guattari, Félix. Chaosmosis: An Ethico-aesthetic Paradigm. Bloomington: Indiana UP, 1995. Print.

27 Puar, Jasbir K. "Prognosis Time: Towards a Geopolitics of Affect, Debility and Capacity." Women \& Performance: A Journal of Feminist Theory19.2 (2009): 161-72. Web. 


\section{Bibliography}

Baggs, M. (2007). “In My Language.” [video online] Available at: https://www. youtube.com/watch?v=JnylM1hl2jc [Accessed: 1st Dec. 2014].

Berlant, L. (2007) "Slow Death (Sovereignty, Obesity, Lateral Agency)." Critical Inquiry, 33 (4), 754-80.

Blanchot, M. (1986)The Writing of the Disaster (L'ecriture Du Désastre). Lincoln: U of Nebraska.

Deleuze, G. (1997) Essays Critical and Clinical. Minneapolis: U of Minnesota.

Guattari, F. (1995) Chaosmosis: An Ethico-aesthetic Paradigm. Bloomington: Indiana UP.

James, W. (2008)The Varieties of Religious Experience: A Study in Human Nature. N.p.: Arc Manor LLC.

Kohn, D. (2003). "Breaking The Silence: One Woman's Drive to Teach Her Autistic Son." CBS Interactive [online] 14th Jan. Retrieved from: http://www.cbsnews. com/news/breaking-the-silence-14-01-2003/ [Accessed: 26th Oct. 2014].

Manning, E. (2013) Always More than One: Individuation's Dance. Durham: Duke UP.

Mukhopadhyay, T.(2003) The Mind Tree: A Miraculous Child Breaks the Silence of Autism. New York: Arcade Pub.

Murray, S. (2008) Representing Autism: Culture, Narrative, Fascination. Liverpool: Liverpool UP.

Puar, J. (2009) "Prognosis Time: Towards a Geopolitics of Affect, Debility and Capacity." Women \& Performance: A Journal of Feminist Theory, 19 (2), 161-72.

Savarese, R.(2010) "Toward a Postcolonial Neurology: Autism, Tito Mukhopadhyay, and a New Geo-poetics of the Body." Journal of Literary \& Cultural Disability Studies, 4 (3), 273-89.

Sha, X. (2012)Poiesis and Enchantment in Topological Matter. Cambridge, MA: MIT.

Whitehead, A., and Price, L. (1954) Dialogues of Alfred North Whitehead. Boston: Little, Brown. 